\title{
The effect of intravenous ketamine and pethidine on postoperative shivering in surgical patients under general anesthesia in Tikur anbessa specialized hospital, Addis Ababa, Ethiopia: A prospective observational cohort study
}

Geresu Gebeyehu ( $\nabla$ geressu.gebeyehu@aau.edu.et)

department of Anesthesia, College of Health sciences, Addis Ababa University, Addis Ababa Ethiopia Betelihem Girma

department of Anesthesia, College of Health sciences, Addis Ababa University, Addis Ababa Ethiopia

Research Article

Keywords: elective surgery, general anesthesia, ketamine, pethidine, postoperative shivering

Posted Date: April 27th, 2021

DOI: https://doi.org/10.21203/rs.3.rs-403682/v2

License: (c) (i) This work is licensed under a Creative Commons Attribution 4.0 International License.

Read Full License 


\section{Abstract}

Background: Postanesthesia shivering is one of the potential complications of anesthesia which may increase patient morbidity. Various methods have been employed to control postoperative shivering. This study assessed the effectiveness of prophylactic low-dose intravenous ketamine and pethidine for postoperative shivering after general anesthesia.

Methods and materials: This prospective cohort study recruited 76 ASA I and II patients aged 18-65 years old and underwent elective surgery under general anesthesia. The patients were grouped based on either ketamine $0.5 \mathrm{mg} / \mathrm{kg}$ or pethidine $0.5 \mathrm{mg} / \mathrm{kg}$ having been administered by the anaesthetist in charge as a prophylaxis for postoperative shivering 20 minutes before completion of the surgery. The incidence and severity of postoperative shivering were compared between the two groups every 10 minutes until one hour postoperatively. The side effects of the study drugs were also compared between the two groups in the recovery room. Categorical data were analyzed with the Chi-Square test. Parametric and nonparametric data between the groups were analyzed using independent samples t-test and MannWhitney $\mathrm{U}$ test, respectively. A p-value of $<0.05$ was considered statistically significant.

Results: The incidence of shivering between the ketamine and pethidine groups was $11(28.2 \%)$ and $14(35.9 \%)$, respectively $(p=0.467)$. The severity of shivering was not significantly different between the two groups ( $p=0.893)$. The occurrence of nausea and vomiting and sedation attributed to the drugs was significantly less in the ketamine group $(p<0.05)$. PACU stay duration and occurrence of hallucinations among the groups were comparable. $(p>0.05)$

Conclusion and Recommendation: This study revealed administering low-dose IV ketamine $(0.5 \mathrm{mg} / \mathrm{kg})$ 20 minutes before completion of surgery reduced postoperative shivering as nearly equally as pethidine. The study also showed clinically better outcomes in favor of ketamine since it was associated with fewer side effects. Thus, we recommend low-dose IV ketamine 20 minutes before completion of surgery under general anesthesia to prevent postoperative shivering.

\section{Introduction}

Shivering after surgery under general anesthesia is a widespread problem with an incidence of $65 \%$ but varies in severity. It can sometimes cause a great deal of discomfort in surgical patients recovering from general anesthesia. [1, 2] Moreover, it may have deleterious sequelae in the postoperative period, ,e. increased oxygen consumption, increased $\mathrm{CO} 2$ production, increased risk of postoperative hypoxemia, increased catecholamine release, increased cardiac workload and risk of perioperative myocardial ischemia, increased recovery room stay, and disturbing the reading of monitors. [3], The problem is more pronounced in developing countries where surgery is undertaken in a poorly equipped and devoid of a perioperative temperature control system and poorly practiced modern anesthetics, l,e. predominantly using volatile anesthetics. $[4,5)]$ 
While there were different pharmacological and nonpharmacological methods tried in the past to control shivering that occurs intraoperatively and postoperatively, no novel methods and treatment modalities were discovered so far. [6], Pharmacological agents used to prevent or treat post-operative shivering including alfentanil, sufentanil, ketanserin, physostigmine, nefopam, urapidil, doxapram, tramadol, nalbuphine, and pethidine, but the ideal drug for this query has become questionable. [7], Among these drugs, pethidine is the most effective drug, but disadvantages I,e, nausea, vomiting, hallucinations, and respiratory depression precludes its utilization. $[8,9,18]$

At several levels, $\mathrm{N}$-methyl-d-aspartate receptor antagonists are likely to modulate thermoregulation. Ketamine, the NMDA receptor competitive antagonist, has different characteristics such as cerebral vasodilatation, induction of relaxation of bronchial smooth muscle, amnesia, ability to increase intracranial pressure, cause transient, and marked increase of blood pressure by sympathetic system stimulation, and analgesia. Ketamine can likely control shivering as a prophylactic agent. [4, 9, 10], This study compared the effect of prophylactic low-dose ketamine and pethidine as a way of preventing postoperative shivering after general anesthesia.

\section{Methodology}

After obtaining ethical approval from the institutional ethics committee of Addis Ababa University, College of health sciences, a prospective cohort study was conducted from January 01 to April 30, 2018, at Tikur Anbessa specialized hospital, Addis Ababa Ethiopia. The study involved 76 ASA I and II patients aged 18-65 years old undergoing elective surgery under general anesthesia. Sample size was calculated to compare two proportions based on the following assumptions: significance level $5 \%(a=0.05)$, and a power of study $(1-\beta)$ of $80 \%$. From a previous studies, the effectiveness of pethidine $0.5 \mathrm{mg} / \mathrm{kg}$ and ketamine $0.5 \mathrm{mg} / \mathrm{kg}$ in preventing postoperative shivering was found to be $88.9 \%$ and $62.2 \%$ respectively [zabareh SMHT, et al. 2012], thus it's computed as follows:

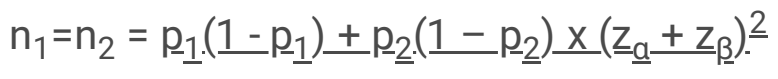

$$
\left(p_{1}-p_{2}\right)^{2}
$$

$=(\underline{0.889})(\underline{0.111}) \pm(\underline{0.622})(\underline{0.378}) \underline{x 7.84}=37$ per each group.

$(0.889-0.622)^{2}$

Where,

$\mathrm{n}_{1}=$ number of clients to take pethidine

$\mathrm{n}_{2}=$ number of clients with take ketamine

$Z=95 \%$ confidence interval $=1.96$ 
$F(a, \beta)=$ power function at $80 \%=7.84$

$\mathrm{P}_{1}=$ Efficacy in percentage for pethidine (88.9\%), Q1 is 1-P1 (11.1\%)

$P_{2}=$ Efficacy in percentage for ketamine (62.2\%), Q2 is 1-P2 (37.8\%)

By considering a contingency of $5 \%$, the study involved 39 individuals. Thus, the total sample for both groups was $39 \times 2=78$. Two participants were excluded because of loss to follow-up. Thus, 76 participants completed the study.

The informed consent was obtained from each participant to be involved in the study. The participants were selected using a systematic random sampling technique.

Patients induced with ketamine, $\mathrm{BMI}>30$, thyrotoxicosis, psychiatric problems, patients taking blood transfusion, hypertensive patients, and convulsions and other psychiatric disorders were excluded from the study. The anesthetic management of patients in both groups was according to the hospital's routine practice guidelines. Anesthesia was induced with propofol $2 \mathrm{mg} / \mathrm{kg}$, morphine $0.1 \mathrm{mg} / \mathrm{kg}$, and vecuronium $0.1 \mathrm{mg} / \mathrm{kg}$ to facilitate tracheal intubation. Anesthesia maintenance was using intermittent bolus vecuronium $0.1 \mathrm{mg} / \mathrm{kg}$ and halothane $1-1.5 \%$. In all patients, no active warming had been utilized throughout the procedure. Patients were monitored using ASA standard monitors. Body temperature was measured and recorded in all participants using an axillary thermometer starting from the preoperative period and at different time intervals intraoperatively and every 10 minutes until one hour postoperatively. In our hospital, pethidine was a well-known drug to control perioperative shivering, and therefore routinely used used to treat it once it occurred; some anaesthetists use low dose ketamine prophylaxis instead of pethidine because of associated side effects such as respiratory depression, addiction, nausea and vomiting. Thus, at 20 minutes to complete the surgery, the anaesthetist incharge gives either ketamine $0.5 \mathrm{mg} / \mathrm{kg}$ IV or pethidine $0.5 \mathrm{mg} / \mathrm{kg}$ IV as prophylaxis for postoperative shivering. At the end of the surgery, the trachea was extubated after successful antagonism of neuromuscular blockade with neostigmine $0.04 \mathrm{mg} / \mathrm{kg}$ and atropine $0.02 \mathrm{mg} / \mathrm{kg}$.

Patients were transferred to PACU once adequate depth and rate of respiration were ensured, and responded to commands. Patients were monitored as per guidelines in the recovery room. The body temperature measurement continues until 60 minutes in PACU.every 10 minutes interval. Moreover, patients were observed for the occurrence and severity of shivering and side effects of the study drugs after arrival in PACU. The severity of shivering was evaluated by a 5-grade scale similar to that validated by Zabareh SMHT, Morovati L, and koushki AM. [12] (Grade 0: no shivering, grade I: peripheral vasoconstriction, grade II: shivering involving one muscle group only, grade III: shivering in more than one muscle group, and grade IV: shivering involving the whole body). Drug side effects like hallucinations, sedation, nausea, and vomiting were observed in the postoperative period.

The data was analyzed using SPSS version 20 after it were cleaned and coded. Independent samples ttest and Mann-Whitney $U$ test were used for quantitative data analysis that was distributed normally and 
nonnormally respectively. A Chi-square test was used to analyze categorical data. Shapiro Wilks and Levene's tests were used for check the normality of data and homogeneity of variances, respectively. A Pvalue of less than 0.05 was considered a statistically significant difference in observations.

\section{Results}

A total of seventy-six ASA I and II patients were enrolled in the study and were grouped into ketamine and pethidine group, with each group containing 38 patients to compare the effectiveness of low-dose ketamine and pethidine as a way of preventing postoperative shivering. The comparison of demographic and operative characteristics including age, sex, height, weight, BMI, and ASA showed no significant difference between the two groups. (Table I)

The comparison of intraoperative factors such as type and duration of surgery, amount of blood loss, and total fluid administered has shown no statistically significant difference between the groups. (Table II)

Perioperatibe body temperature was recorded and compared between the two groups and has shown no significant difference between the groups. (Table III)

The number of shivering patients in the ketamine and pethidine groups was $11(29 \%)$ and $14(36.8 \%)$, respectively $(p=0.467)$.

The severity of shivering between the two groups was compared and no statistically significant difference was observed. (Figure I)

The patients were observed for possible side effects such as sedation, hallucinations, nausea, and vomiting, and duration of PACU stay. (Table IV) (Figure II)

\section{Discussions}

Postoperative shivering has remained one of the common adverse events in patients recovering from general anesthesia. Furthermore, it is associated with a major deal of discomfort to both the patients and the medical care team. This prospective observational study compared the effectiveness of prophylactic intravenous ketamine $0.5 \mathrm{mg} / \mathrm{kg}$ and pethidine $0.5 \mathrm{mg} / \mathrm{kg}$ in elective surgical patients under general anesthesia.

The antishivering effect of pethidine was suggested by several reports. Its antishivering effect pertains to the k- opioid receptor but not due to $\mu$-receptor-mediated. $[9,11,12]$, Even though it has been a novel antishivering drug, side effects related to pethidine preclude its utilization in some situations. [13]

The preventive effect of ketamine for postoperative shivering was realized in many studies. However, its mechanism of action became difficult to predict due to the pharmacological complexity of the drug. The possible speculation for its antishivering effect would be its action on the thermoregulatory center via 
NMDA antagonism. Inhibition of NE reuptake at the postganglionic fibers by ketamine induces peripheral vasoconstriction which in turn decreases core to peripheral redistribution of heat. $[11,12,14]$

In this study, demographic factors like age, gender, weight, height, ASA physical status, and BMI were all found to be comparable between the two groups; the type and duration of surgery, amount of blood loss and total fluid intake which were considered as risk factors for perioperative hypothermia and shivering [15], were all comparable between the two groups $(p>0.05)$.

In this study, the overall incidence of postoperative shivering was $32.1 \%$. This rate is higher than the report from the study conducted in Isfahan University of Medical Sciences, Iran, by Zabareh SMHT et al. In their study, the overall shivering rate was $26.7 \%$, which is smaller than the rate of our study. [12], The cause for this might be a variation in intraoperative and postoperative patient management. Another speculation could be intraoperative use of fentanyl, which also has an anti-shivering effect, and higher operation room ambient temperature in their study.

In this study, the number of shivering patients was $11(28.2 \%)$ and $14(35.9 \%), p=0.467$ for ketamine and pethidine groups respectively. Although the difference was statistically insignificant, it seems practically a better outcome in favor of ketamine. This finding is in line with the study conducted in India by Dar AM et al. Their study showed no statistically significant difference was found between ketamine and pethidine groups $(p>0.05)$. [16], This might be due to the utilization of the same dose of the study drugs. Another study conducted in Mashhad, Iran, by Masomeh et al. also reported pethidine and ketamine can similarly reduce postoperative shivering [17]. Our study results was also supported by a study in Tabriz University of Medical Sciences, Iran, by Eydi M. et al. in 2014. [18], The results of their study showed that ketamine and pethidine are both equally effective in reducing postoperative shivering. This could be due to a similar study design. Moreover, another study, conducted by Ayatollahi $V$ et al. in Iran has reported a similar finding to our study. Their study reported the prophylactic use of low doses of intravenous ketamine ( 0.3 or $0.5 \mathrm{mg} / \mathrm{kg}$ ) was found to be effective to prevent postanesthetic shivering. However, administration of $0.3 \mathrm{mg} / \mathrm{kg}$ ketamine lowered the rate of hallucination as compared with $0.5 \mathrm{mg} / \mathrm{kg}$. [13], This might be related to different drug responses. A prospective RCT conducted in Isfahan University of Medical Sciences, Iran, by Zabareh SMHT et al. reported a contradictory finding in favor of pethidine. They said pethidine seems to be the most appropriate choice for preventing postoperative shivering. [12],The differences in the study design could have contributed to this discrepancy.

Another prospective randomized study conducted by Emine Arzu et al. in Hacceteppe University, Turkey, showed ketamine in doses of $0.5-0.75 \mathrm{mg} / \mathrm{kg}$ had better reduced postoperative shivering than pethidine. However, ketamine $0.75 \mathrm{mg} / \mathrm{kg}$ associated with more hallucinations. [19], This might be caused by a higher dose of ketamine. Another contradictory result to our findings was reported by the study conducted in Motahari Hospital in Jahrom (Iran), by Zabetian H et al. in 2016. [20], The possible explanation could be due to the usage of a small dose of ketamine than this study.

The severity of postoperative shivering was compared between the two groups and the difference was not statistically significant $(p=0.874)$. A randomized double-blind study conducted by Dar AM et al. 
showed similar findings to this study. The number of patients with grade 1 shivering was 7 and 9 in ketamine and pethidine group, respectively, while 3 patients in each group developed grade shivering. This result is in line with the prospective RCT conducted by Masomeh et al. [17] In their study, while only one patient in the ketamine group developed grade 1 shivering, no patient has developed either grade 2 or 3 shiverings. However, their finding for the pethidine group was similar to the result of this study. This could be due to the less dose pethidine used to prevent postoperative shivering. This study was also supported by a randomized study conducted by Dar AM et al., which showed the number of patients with grade 1 and 2 shivering were 4 and 3 in both ketamine and pethidine groups respectively $(p>0.05)$.

Body temperature between the two groups was recorded and compared in the operation theatre and in the PACU and has shown no statistical difference $(p>0.05)$ except the record at one hour in PACU $(p=0.007)$. There is no factor discovered for the difference at one hour but might be the patient factor and difference in temperature management protocol in PACU. In this study, the mean axillary temperature was lower during intraoperative time compared to the baseline score in both groups. The drop between the two groups was not significantly different $(p>0.05)$. There might have a clinical significance for this difference and could be due to anesthetic induced impairment of thermoregulatory center, decreased metabolic heat production, or core to peripheral redistribution of heat, and heat transfer through an exposed surgical wound. Another study conducted by Zabareh et al. also revealed no difference in perioperative body temperature among patients who took ketamine and pethidine. [12], However, the scores in our results were slightly lower when compared with the values of their study. The probable reason could be due to the controlled room temperature $\left(22-25^{\circ} \mathrm{c}\right)$ in their study, but our study lacks to control ambient temperature.

In this study, side effects like hallucinations, nausea, and vomiting, duration of PACU stay, and sedation associated with the study drugs were compared between the two groups.

The number of sedated patients was significantly higher in pethidine than ketamine group: $6(15.8 \%)$ versus $16(42.1 \%)$ for ketamine and pethidine groups respectively, $p=0.012$. This could be due to differences in the duration of elimination for ketamine and pethidine. Another difference might be due to the combined effects of pethidine with intraoperative morphine, inhalational anesthetics, and perioperative hypothermia.

In this study, nausea and vomiting were observed among the groups and found to be significantly different, $p=0.025$. The possible explanation could be opioid-induced activation of the chemoreceptor trigger zone.

PACU stay time between the groups was found to be comparable ( $48.85 \pm 6.73$ and $50.13 \pm 5.90$ minutes for ketamine and pethidine groups, respectively, $p=0.374$ ). The result of a study conducted in Iran by Ayatollahi et al. revealed the duration of PACU stay for ketamine and pethidine groups was $64.50 \pm 1.43$ minutes and $56.67 \pm 1.27$ minutes respectively. [14] In the same study, the length of PACU stay was 49.37 \pm 1.22 minutes and $43.10 \pm 1.60$ minutes in those who took ketamine $0.3 \mathrm{mg} / \mathrm{kg}$ and control group. Thus, 
PACU stay time in the previous groups was slightly longer. The reason could be attributed to the higher dose of study drugs.

This is the first study in our country; thus it could be an important source of information for clinical researchers. However, the lack of randomization and control for room temperature and the temperature of intravenous fluids in the institution might be the limitation of this study.

\section{Conclusion}

This study has proved prophylactic low-dose ketamine could prevent postoperative shivering as equally as pethidine and associated with fewer side effects. We recommend using ketamine $0.5 \mathrm{mg} / \mathrm{kg} 20$ minutes before the end of the operation to prevent postoperative shivering. We also recommend ketamine because it is easily available in the operation room and cost-effective.

\section{Declarations}

Conflicts of interests: none

Funding sources: Addis Ababa University

\section{Acknowledgments}

The authors would like to thank the almighty GOD for all his support. Our gratitude also goes to Addis Ababa University, College of Health Sciences, Department of Anesthesia for their cooperation to invest our time in this study and those who provided constructive support to this research project. We would also like to thank Tikur Anbessa specialized hospital anesthetists, staff members, and participants for their voluntariness to facilitate the study process.

\section{Abbreviations}

ASA American society of anesthesiologists

BMI, $\quad$ Body mass index

$\mathrm{CO}_{2} \quad$ Carbon dioxide

ECG Electrocardiography

GA General Anesthesia

IV Intravenous

NMDA N-methyl-D aspartate 
PACU Postanesthesia care unit

PAS Post-anesthesia shivering

\section{References}

1. Horn EP, Sessler DI, Standl T, Schroeder F, Bartz HJ, Beyer JC, and Schulte am Esch J. Nonthermoregulatory shivering in patients recovering from isoflurane or desflurane anesthesia. Anesthesiology 1998; 89 (4): 878-86.

2. Schafer M, Kunitz O. Postoperative shivering. Anaesthesist. 2002;51(9):768-84. DOI: 10.1007/s00101-002-0381-y. [PubMed: 12232650]

3. Morgan A and Mikhail M: Clinical Anesthesiology. New York: A Lange Medical book; 2013, 5th Ed.

4. Kose EA, Dal D, Akinci SB, Saricaoglu F, Aypar U. The efficacy of ketamine for the treatment of postoperative shivering. AnesthAnalg. 2008; 106(1):120-2.

5. Rastegarian A, Ghobadifar MA, Kargar H, Mosallanezhad Z. IntrathecalMeperidine Plus Lidocaine for Prevention of Shivering during the Cesarean Section. Korean J Pain. 2013; 26(4):379-86. DOI: 10.3344/kjp.2013.26.4.379. [PubMed: 24156005].

6. Bhattacharya, Bhattacharya L, Jain R, Agarwal R, post-anesthesia shivering(PAS): A Review. Indian J. Anesth.2003; 47(2); 88-93.

7. Dhiman AA, Patel MG, Swadia VN. Tramadol for control of shivering (comparison with pethidine). Indian Journal of Anaesthesia. 2007 Jan 1; 51(1):28.

8. Bahman Hasannasab, Nadia Banihashem, Arash Khoshbakht. Prophylactic Effects of Doxapram, Ketamine, and Meperidine in Postoperative Shivering. Anesth Pain Med. 2016;6(1):e27515:1-4

9. Dal D, Kose A, Honca M, Akinci SB, Basgul E, Aypar U. Efficacy of prophylactic ketamine in preventing postoperative shivering. Br J Anaesth.2005; 95(2): 189-92.

10. Singh P, Dimitriou V, Mahajan PR, Crossley AW. A double-blind comparison between doxapram and pethidine in the treatment of postanaesthetic shivering. $\mathrm{Br} \mathrm{J}$ Anaesth 1993; 71: 685-8.

11. De Witte J, Sesler DI. Perioperative shivering: physiology and pharmacology. Anesthesiology 2002; 96(2): 467-84.

12. Zabareh SMHT, Morovati L, koushki AM. A comparative study on the prophylactic effects of ketamine, dexamethasone, and pethidine in preventing postoperative shivering.Journal of Research in Medical Sciences; March 2012 Special Issue (2): 175 - 81.

13. Ayatollahi V, hajiesmaeili MR, Behdad S, GholifurM, Abbasi HR. Comparison of prophylactic use of meperidine and two low doses of ketamine for prevention of post-anesthetic shivering: A randomized double-blind placebo-controlled trial. J Res Med Sci 2011; 16(10): 1340-46

14. Ikeda T, Kazama T, Sessler DI, ToriyamaS,Niwa K, Shimada C, and Sato S. Induction of Anesthesia with Ketamine Reduces the magnitude of Redistribution Hypothermia.AnesthAnalg 2001;93:934-8 
15. Eberhart LHJ, Döderlein F, Eisenhardt G, Kranke P, Sessler DI, Torossian A, et al. Independent risk factors for postoperative shivering. AnesthAnalg.2005; 101(6): 1849-57.

16. Dar AM, Qazi SM, Sidiq S.A placebo-controlled comparison of ketamine with pethidine for the prevention of postoperative shivering.SouthAfr J AnaesthAnalg 2012; 18(6):340-43

17. Masomeh T, Ghassem S, Fariba H, Shahram A. Effect of Intravenous Ketamine on Prevention of Postoperative Shivering: A Comparison with Intravenous Pethidine. Journal of Surgery and Trauma 2014; 2(1): $1-5$

18. Eydi M, Golzari SE, Aghamohammadi D, Kolahdouzan K, Safari S, Ostadi Z. Postoperative management of shivering: a comparison of pethidine vs. ketamine. Anesthesiology and pain medicine. 2014 May;4(2).

19. Emine Arzu Kose, Didem Dal, Seda Banu Akinci, FatmaSaricaoglu, UlkuAypar.The Efficacy of Ketamine for the Treatment of Postoperative Shivering.AnesthAnalg 2008;106:120 - 2.

20. Zabetian H, Kalani N, Sanie MS, Deylami M, Kargar Jahrom H, Poorgholami F. A Comparative Study on Different Doses of Pethidine and Ketamine for Prevention of Shivering During and After Spinal Anesthesia at Cesarean Section. International Journal of Medical Research \& Health Sciences. 2016;5(5):303-7.

\section{Tables}

Table l: Demographic characteristics and operative values of elective surgical patients under general anesthesia at Tikur Anbessa specialized hospital, Addis Ababa Ethiopia

\begin{tabular}{|llll|}
\hline & Ketamine group & Pethidine group & P-value \\
\hline Age & $42.95 \pm 11.82$ & $41.74 \pm 12.49$ & 0.663 \\
\hline Gender(M/F) & $20 / 19$ & $21 / 18$ & 0.821 \\
\hline Height & $166.15 \pm 5.52$ & $167.36 \pm 5.80$ & 0.350 \\
\hline Weight & $62.23 \pm 8.31$ & $64.26 \pm 5.48$ & 0.208 \\
\hline BMI & $22.47 \pm 2.36$ & $23.02 \pm 1.17$ & 0.196 \\
\hline ASA(I/II) & $24 / 15$ & $21 / 18$ & 0.492 \\
\hline
\end{tabular}

Table II: Intraoperative exposure variables in elective surgical patients under general anesthesia at Tikur Anbessa specialized hospital, Addis Ababa Ethiopia 


\begin{tabular}{|llll|}
\hline variables & Ketamine group & Pethidine group & P-value \\
\hline Types of surgery & & & \\
Abdominal surgery & 14 & 12 & \\
Gynecologic surgery & 10 & 12 & 0.932 \\
Orthopedic surgery & 10 & 11 & \\
Urologic surgery & 5 & 4 & \\
& & & \\
Duration of surgery(minute) & $124.51 \pm 24.27$ & $130.25 \pm 30.45$ & 0.360 \\
\hline & & & 0.868 \\
\hline
\end{tabular}

Type of surgery presented in numbers, others in mean \pm SD.

Table III: Perioperative Body Temperature of elective surgical patients under general anesthesia at Tikur Anbessa specialized hospital, Addis Ababa Ethiopia 


\begin{tabular}{|c|c|c|c|c|c|}
\hline \multicolumn{6}{|l|}{ Variables } \\
\hline & & & $\begin{array}{l}\text { Ketamine } \\
\text { group }\end{array}$ & $\begin{array}{l}\text { Pethidine } \\
\text { group }\end{array}$ & $\begin{array}{l}P \\
\text { value }\end{array}$ \\
\hline \multirow{13}{*}{$\begin{array}{r}\text { Body } \\
\text { temperature }\left({ }^{\circ} \mathrm{C}\right)\end{array}$} & \multirow{6}{*}{$\begin{array}{l}\text { Operation } \\
\text { room }\end{array}$} & Baseline & $36.32 \pm 0.26$ & $36.27 \pm 0.27$ & 0.332 \\
\hline & & $\begin{array}{l}\text { Before the study drugs } \\
\text { given }\end{array}$ & $35.58 \pm 0.49$ & $35.41 \pm 0.54$ & 0.143 \\
\hline & & $\begin{array}{l}5 \text { minutes after the } \\
\text { study drugs given }\end{array}$ & $35.33 \pm 0.53$ & $35.26 \pm 0.46$ & 0.571 \\
\hline & & $\begin{array}{l}10 \text { minutes after study } \\
\text { drugs given }\end{array}$ & $35.27 \pm 0.50$ & $35.10 \pm 0.56$ & 0.160 \\
\hline & & $\begin{array}{l}15 \text { minutes after study } \\
\text { drugs given }\end{array}$ & $35.18 \pm 0.58$ & $35.09 \pm 0.36$ & 0.452 \\
\hline & & $\begin{array}{l}20 \text { minutes after study } \\
\text { drugs given }\end{array}$ & $34.99 \pm 0.37$ & $34.90 \pm 0.39$ & 0.288 \\
\hline & \multirow{7}{*}{ PACU } & T0 & $35.09 \pm 0.56$ & $34.9 \pm 0.45$ & 0.106 \\
\hline & & T10 & $34.93 \pm 0.53$ & $34.74 \pm 0.48$ & 0.101 \\
\hline & & T20 & $35.16 \pm 0.41$ & $35.07 \pm 0.26$ & 0.295 \\
\hline & & T30 & $35.14 \pm 0.33$ & $35.04 \pm 0.23$ & 0.129 \\
\hline & & T40 & $34.98 \pm 0.42$ & $35.01 \pm 0.36$ & 0.752 \\
\hline & & T50 & $35.00 \pm 0.24$ & $34.89 \pm 0.32$ & 0.810 \\
\hline & & T60 & $35.01 \pm 0.51$ & $34.71 \pm 0.48$ & 0.007 \\
\hline
\end{tabular}

The values are stated as mean and standard deviation

Table IV: The side effects of study drugs in elective surgical patients under general anesthesia 


\begin{tabular}{|lccc|}
\hline & & & \\
& Ketamine group & Pethidine group & P-value \\
Sedation & & & \\
Yes & $6(7.9 \%)$ & $16(21 \%)$ & 0.012 \\
No & $32(92.1 \%)$ & $11(79 \%)$ & \\
& & & \\
& & & \\
\hline PACU stay (minutes) & $48.85 \pm 6.73$ & $50.13 \pm 5.90$ & 0.374 \\
\hline Nausea and vomiting & 1 & 7 & 0.025 \\
\hline Hallucination & 3 & 1 & 0.305 \\
\hline
\end{tabular}

Sedation, nausea and vomiting, and hallucination are described in numbers, PACU stay time described in mean+ SD. SD: standard deviation

\section{Figures}

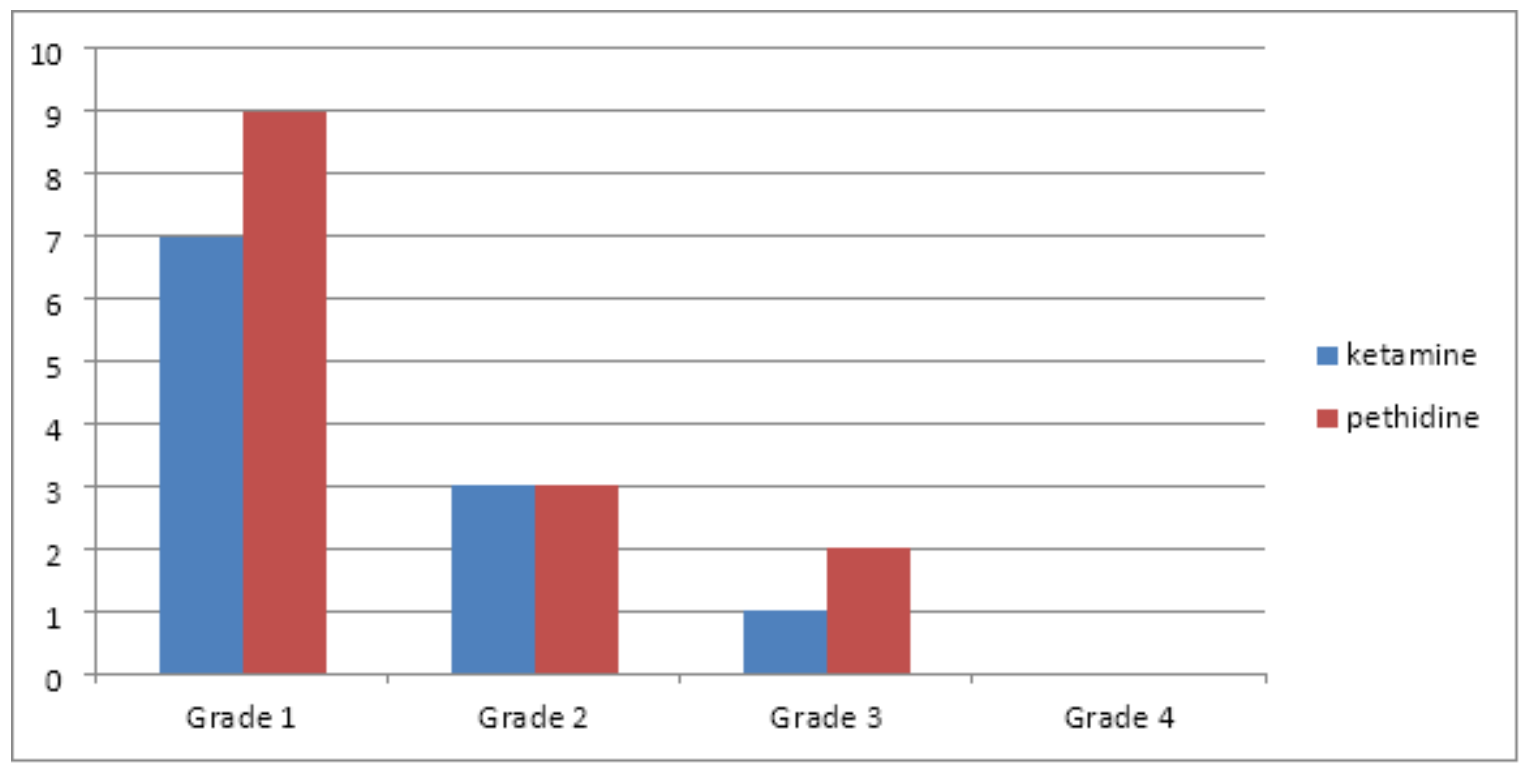

Figure 1

Bar graphs displaying the severity of postoperative shivering in elective surgical patients under general anesthesia. 


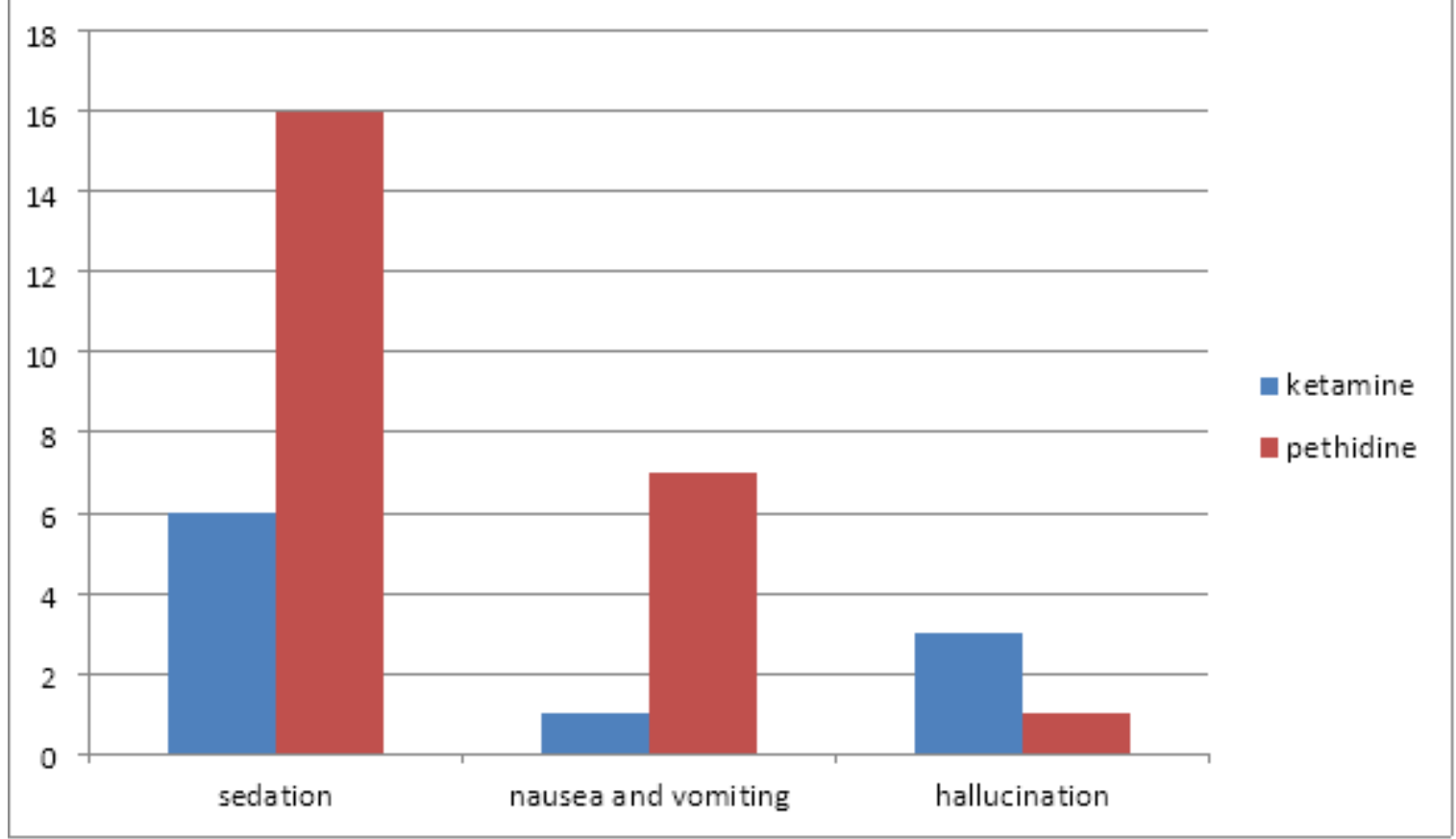

Figure 2

Bar graphs showing side-effects among elective surgical patients under general anesthesia. 